\title{
ANÁLISE DO NÚMERO DE CASOS DE ACIDENTES POR ANIMAIS PEÇONHENTOS NO ESTADO DE SÃO PAULO, BRASIL NO ANO DE 2014
}

\author{
ANALYSIS OF THE CASES OF ACCIDENTS BY POISONOUS ANIMALS IN THE \\ STATE OF SÃO PAULO, BRAZIL IN 2014 YEAR
}

\author{
E. M. N. PAULA ${ }^{1 *}$, C. A. CRUZ ${ }^{2}$, C. S. L. NOGUEIRA ${ }^{2}$, R. B. MEIRELLES-BARTOLI ${ }^{1}$, \\ A. A. B. CARVALHO ${ }^{2}$
}

\begin{abstract}
RESUMO
Os acidentes por animais peçonhentos constituem sério problema de saúde pública, principalmente nos países tropicais, em virtude de sua grande frequência e gravidade. A correta identificação e notificação das espécies animais envolvidas nesse tipo de acidente são imprescindíveis, uma vez que a partir dessas informações é possível estabelecer melhores estratégias que auxiliem na redução de novos casos. $\mathrm{O}$ objetivo desse estudo foi determinar o número de casos bem como as espécies envolvidas em acidentes causados por animais peçonhentos no Estado de São Paulo ao longo do ano de 2014. Trata-se de um estudo descritivo utilizando-se dados secundários referentes ao ano em questão, obtidos por meio de um levantamento realizado no sistema de informação do Centro de Vigilância Epidemiológica. Entre os meses de janeiro a dezembro de 2014, foram notificados 22.519 casos de agravos por animais peçonhentos em todo o Estado de São Paulo. Sendo que destes, 12.513 foram ocasionados por escorpião e 3.543 por aranhas, $55,56 \%$ e $15,73 \%$, respectivamente. Em terceiro lugar, tem-se os acidentes causados por abelhas, representando $11,75 \%$ (2.648 casos) do total. As serpentes foram responsáveis por um montante de 1.980 casos. Por fim, foram notificados 379 acidentes por lagartas. Um dado importante, encontrado nesse estudo, é o fato de que 759 casos foram notificados, entretanto, não ocorreu a especificação da espécie agressora. Esse tipo de ação atrapalha as avaliações epidemiológicas, e dificulta o estabelecimento estratégico de medidas preventivas. Com base nesse estudo, nota-se que ainda é grande o número de casos de acidentes por esses tipos de animais na região do Estado de São Paulo. Com a avaliação das principais espécies agressoras envolvidas pode-se propor ações educativas destinadas à população mais susceptível, buscando-se reduzir a incidência desses acidentes.
\end{abstract}

PALAVRAS-CHAVE: SAÚDE. VIGILÂNCIA EPIDEMIOLÓGICA. ANIMAIS PEÇONHENTOS.

ÁREA TEMÁTICA: Saúde Pública

\footnotetext{
${ }^{1}$ Universidade Federal de Goiás (UFG), Regional Jataí, Unidade Jatobá, Laboratório de Sanidade Animal ${ }^{2}$ Faculdade de Ciências Agrárias e Veterinárias da Universidade Estadual Paulista (UNESP) - Câmpus de Jaboticabal

* eric.gyn@gmail.com
} 